Research Article

\title{
Measuring Interest Rate Risk with Embedded Option Using HPL-MC Method in Fuzzy and Stochastic Environment
}

\author{
Enlin Tang $\mathbb{D}^{1}$ and Wei Du $\mathbb{D}^{2}$ \\ ${ }^{1}$ School of Finance and Mathematics, Huainan Normal University, Huainan 232038, China \\ ${ }^{2}$ School of Mathematics and Statistics, Hefei Normal University, Hefei 230601, China \\ Correspondence should be addressed to Wei Du; duwei@hfnu.edu.cn
}

Received 22 August 2020; Revised 21 September 2020; Accepted 25 September 2020; Published 15 October 2020

Academic Editor: Ahmed Mostafa Khalil

Copyright ( 2020 Enlin Tang and Wei Du. This is an open access article distributed under the Creative Commons Attribution License, which permits unrestricted use, distribution, and reproduction in any medium, provided the original work is properly cited.

\begin{abstract}
Under the condition of continuous innovation of financial derivatives and marketization of interest rate, interest rates fluctuate more frequently and fiercely, and the measurement of interest rate risk also attracts more attention. Under the premise that the fluctuation of interest rate follows fuzzy stochastic process, based on the option characteristics of financial instruments with embedded option, this paper takes effective duration and effective convexity as tools to measure interest rate risk when embedded options exist, tries to choose CIR extended model as term structure model, and uses the Monte Carlo method for hybrid low deviation sequences (HPL-MC) to analyze the prepayment characteristics of MBS, a representative financial instrument with embedded options, when interest rates fluctuate; on this basis, the effectiveness of effective duration management of interest rate risk is demonstrated with asset liability management cases of commercial banks.
\end{abstract}

\section{Introduction}

With the further acceleration of the process of global economic integration, the global financial liberalization and facilitation reform with the financial innovation of developed countries and the financial deepening of developing countries as the main content is becoming more and more intense; a country's financial market can no longer develop in isolation, and it is bound to be integrated into the entire international financial market. On December 13, 2001, China officially became a member of the World Trade Organization (WTO). According to the Financial Services Authority (FSA) of the world trade organization, each member country must make a commitment to open up the financial market and gradually bring $95 \%$ of the global financial service trade into the process of liberalization. As one of the member countries, China's financial system will also be integrated into the world economic globalization, China's monetary policy will be more and more affected by the international monetary policy, and the convergence of China's interest rate changes and international market interest rate changes will become stronger and stronger [1]; the interest rate risk caused by this will become one of the most serious risks faced by commercial banks. At the same time, the frequent fluctuation of interest rates also gives birth to various derivative financial instruments; among them, financial instruments with the characteristics of embedded options such as deposits that can be withdrawn in advance, loans that can be paid in advance, mortgage-backed securities, collateralized mortgage obligation, and callable bonds are more and more embedded in the balance sheets of commercial banks, which greatly increases the difficulty of interest rate risk management of commercial banks. The gap model based on traditional duration and traditional convexity is less effective in interest rate risk management; therefore, it is of great significance to measure and manage the interest rate risk of embedded option financial instruments [2].

Scholars at home and abroad have made some important achievements in the study of interest rate risk of embedded options. Internationally, Brent and Richard proposed the Monte Carlo (MC) simulation pricing 
method for the embedded options belonging to the Asian option type; after estimating the parameters in the model based on this method, the price of embedded option bonds was obtained [3]. Brooks made a sensitivity analysis on the value of embedded options and interest rate level in CDs based on cross-sectional data [4]. Ben-Ameur pointed out that the inconsistency of value changes caused by the mismatch of asset and liability convexity is also the cause of embedded option risk and studied the characteristics of embedded options in commercial bank deposits and the characteristics of depositors' exercise time [5]. Domestic scholars have also made important achievements in the research of embedded options. Zhenlong and Hai decomposed the option characteristics of assets and liabilities in the balance sheet of commercial banks and used the basic principles of financial engineering to price implicit options without arbitrage and also made numerical pricing [6]. Xia et al. built the benchmark interest rate jump model of deposits and conducted the numerical pricing of embedded option deposit and loan based on the Monte Carlo simulation method and studied the impact of embedded options on interest rate risk of China's commercial banks by using comparative analysis method [7]. Li et al. proposed that with the development of interest rate marketization and the continuous innovation of financial instruments of China's commercial banks, embedded options are more and more appearing in the balance sheet of commercial banks, and at the same time, it brings huge interest rate risk to the operation of commercial banks. Therefore, commercial banks urgently need to establish a complete interest rate risk management system in time. However, the traditional risk management methods, such as interest rate sensitivity gap and duration gap, have been unable to meet the interest rate risk management requirements of assets and liabilities with embedded options. The review of the research results at home and abroad shows that the research on embedded options started earlier in foreign countries; although the domestic research started late, it has also made some achievements. Domestic research studies focus on pricing the value of embedded options, but few focus on the measurement and management of interest rate risk of embedded options. In addition, the differential equation method and nonarbitrage pricing method adopted by predecessors are based on a series of strict preconditions. The traditional Monte Carlo simulation method is usually used to calculate the price of embedded option and the effective duration of securities with embedded option; however, the random number sequence generated by traditional MC in the simulation space is unevenly distributed, which wastes a large number of observations and reduces the operation efficiency; therefore, this paper uses a more advanced simulation method, namely, HPL-MC, based on the optimized interest rate risk management tools, namely, effective duration and effective convexity, makes an empirical analysis on the change of characteristics of financial instruments caused by the existence of embedded options, and demonstrates how commercial banks can effectively measure and manage interest rate risk when implicit options exist.

\section{Analysis on the Option Characteristics of Financial Instruments with Embedded Options}

With the increasing types of derivative financial instruments, financial instruments with embedded options are more and more embedded in the assets and liabilities of commercial banks, such as deposits that can be drawn in advance, prepayable loans, collateralized mortgage obligation, callable bonds, mortgage-backed securities, and so on. Here, we will take the prepayment of housing mortgage loans as an example to illustrate.

\subsection{Influencing Factors of Prepayment of Housing Mortgage} Loans. From the perspective of borrowers, the following factors will affect their prepayment behaviors.

2.1.1. Interest Rate Factor. The interest rate factor is the primary factor to decide the prepayment behaviors. The interest rate factor here refers to the balance between the market interest rate and the contract interest rate: the contract interest rate determines the interest expense of the loans and the market interest rate determines the cost of refinancing. Assuming that the borrower prepays at time $t$, the refinancing cost is expressed by $V(t)$, the penalty is $\alpha$, and the loan balance at time $t$ is $L(t)$; when $W(t)=V(t)-$ $[L(t)+\alpha]$ is greater than zero, prepayment will be executed.

2.1.2. Economic Situation. With the improvement of people's economic situation and the improvement of living requirements, the prepayment rate will increase, and at the same time, it will also cause the increase of house purchase rate and turnover rate. In addition, when the national macroeconomic operation is good, the whole real estate market is hot, and when the rise of house price exceeds the balance of mortgage loan, prepayment will appear in large number.

2.1.3. Institutional Factors. The minimum amount of prepayment and the limit of the times of prepayment will restrain the behavior of prepayment to a certain extent. However, the penalty for prepayment of housing mortgage loan is not high in our country, that is to say, the cost of prepayment is small, so prepayment often occurs.

2.1.4. Other Factors. Factors such as relocation, mortgage characteristics, and seasons.

\subsection{The Influence of Prepayment of Housing Mortgage Loan on Commercial Banks}

2.2.1. Positive Impact. Firstly, the prepayment of housing mortgage loan reduces the possibility of nonperforming loan 
and reduces the credit risk. Secondly, the prepayment of housing mortgage loan increases the liquidity of commercial bank assets and improves the response ability of commercial banks to long-term and short-term capital demand and the efficiency of capital utilization.

2.2.2. Negative Effect. Firstly, prepayment reduces the interest margin of deposit and loan greatly, which is the main part of profit for commercial banks, so prepayment will reduce the profit of commercial banks. Secondly, the risk of reinvestment of commercial banks increases; when the market interest rate decreases, commercial banks can only look for investment projects with low return rate, and the reinvestment income is greatly reduced. Thirdly, prepayment destroys the original capital structure, and the asset liability structure based on duration and convexity is no longer matched, resulting in risk exposure. Fourthly, when the market interest rate drops, the prepayment of mortgage loan makes the market value of bank assets have an upper limit. As shown in Figure 1, two curves represent the valueinterest curve of mortgage: the solid line indicates nonprepayment and the dotted line indicates prepayment. When the contract stipulates that the mortgage loan cannot be paid in advance, the decrease of interest rate will cause the asset value of the bank to rise; however, when the interest rate falls to $R^{*}$ ( $R^{*}$ refers to the interest rate level that causes the borrower to prepay, that is, to exercise the embedded option), the value of assets will encounter a bottleneck when the mortgage loan can be repaid in advance, and it will decrease gradually after reaching $P^{\prime}$, which will lead to the decrease of net assets of commercial banks.

2.3. Analysis on the Option Characteristics of Housing Mortgage Loan. For the option characteristics of prepayment of mortgage loans, the following is an example of Case 1.

Case 1. A borrower and a commercial bank sign a loan contract with a term of $T$ at zero time, in which the loan amount is unit 1 , the penalty is $\alpha$, and the lending rate is expressed by continuous compound interest rate $r_{0, T}$. When prepayment is not considered, the total borrowing cost is $e^{r_{0, T} T}$; assuming that the benchmark interest rate changes to $r_{1, T}$ at time $t$, prepayment occurs, and the refinancing cost is $\left(e^{r_{0, T} t}+\alpha\right) e^{r_{1, T}(T-t)}$; if $e^{r_{0, T} T} \geq\left(e^{r_{0, T} t}+\alpha\right) e^{r_{1, T}(T-t)}$, the rational borrower will prepay; otherwise, the prepayment will not be carried out. This method can be used for similar analysis whenever interest rate adjustment occurs.

If expressed by mathematical equation, the borrowing cost of the borrower at time $t$ can be expressed as follows:

$$
\begin{aligned}
- & \min \left[\left(\left(e^{r_{0, T} t}+\alpha\right) e^{r_{1, T}(T-t)}\right), e^{r_{0, T} T}\right] \\
& =-e^{r_{0, T} T}-\min \left[\left(e^{r_{0, T} t}+\alpha\right) e^{r_{1, T}(T-t)}-e^{r_{0, T} T}, 0\right] \\
& =-e^{r_{0, T} T}+\max \left[e^{r_{0, T} T}-\left(e^{r_{0, T} t}+\alpha\right) e^{r_{1, T}(T-t)}, 0\right],
\end{aligned}
$$

where $-e^{r_{0, T} T}$ represents a loan contract with default risk and $\max \left[e^{r_{0, T} T}-\left(e^{r_{0, T} t}+\alpha\right) e^{r_{1, T}(T-t)}, 0\right]^{\prime}$ represents the interest rate call option with the strike price of $K=e^{r_{0, T} T}$ implied in the loan contract.

This kind of housing mortgage loan can be understood as that the borrower issues bonds that can be paid in advance to the bank. This bond contains options, and prepayment can occur at any time before the end of the loan contract; therefore, such a loan contract can be broken down into two parts (as shown in Figure 2):

$A$ : the borrower issues callable bonds to the bank.

$B$ : the bank issues an American callable option to the borrower.

However, banks often ignore $B$ and do not charge option fees to borrowers.

Specifically, with the decline of interest rate, when the cost of refinancing is less than the interest expense of maintaining the original loan, prepayment means "redemption" behavior will occur; such "redemption" right is interest rate put option.

\section{Interest Rate Risk Measurement of Embedded Option Financial Instruments: Effective Duration and Effective Convexity}

3.1. Duration-Convexity Gap Model. By matching the duration and convexity of assets and liabilities, commercial banks can realize the immunity of net assets to interest rate changes and avoid interest rate risk exposure [8]. Let $A$ denote assets, $L$ denote liabilities, and $E$ denote net assets; then, $\mathrm{d} E=\mathrm{d} A-\mathrm{d} L$. Next, we take the second derivative of $A$ and $L$ to get the following equation:

$$
\begin{gathered}
\mathrm{d} A=\frac{\mathrm{d} A}{\mathrm{~d} R_{A}} \mathrm{~d} R_{A}+\frac{1}{2} \frac{\mathrm{d}^{2} A}{\mathrm{~d} R_{A}^{2}}\left(\mathrm{~d} R_{A}\right)^{2}, \\
\mathrm{~d} L=\frac{\mathrm{d} L}{\mathrm{~d} R_{L}} \mathrm{~d} R_{L}+\frac{1}{2} \frac{\mathrm{d}^{2} L}{\mathrm{~d} R_{L}^{2}}\left(d R_{L}\right)^{2} .
\end{gathered}
$$

Let the initial interest rates of $A$ and $L$ be equal, that is, $R_{A}=R_{L}=R$ and $\mathrm{d} R_{A}=\mathrm{d} R_{L}=\mathrm{d} R$. We can get $D_{A}=-\mathrm{d} A / A \mathrm{~d} R, \quad D_{L}=-\mathrm{d} L / L \mathrm{~d} R, \quad C_{A}=-\mathrm{d}^{2} A / A \mathrm{~d} R^{2}$, and $C_{L}=-\mathrm{d}^{2} L / L \mathrm{~d} R^{2}$; then, the expression of $\mathrm{d} E$ is as follows:

$$
\mathrm{d} E=-\left(D_{A}-K D_{L}\right) A \mathrm{~d} R+\frac{1}{2}\left(C_{A}-K C_{L}\right) A(\mathrm{~d} R)^{2},
$$

where $D_{A}$ and $D_{L}$ are the duration of assets and duration of liabilities, $C_{A}$ and $C_{L}$ are the convexity of assets and convexity of liabilities, respectively, and $K=L / A$ is the leverage coefficient, that is, the asset liability ratio. $D_{\mathrm{GAP}}=D_{A}-K D_{L}$ is duration gap, which is used to measure the matching degree of asset duration and liability duration; $C_{\mathrm{GAP}}=C_{A}-$ $K C_{L}$ is convexity gap, which is used to measure the matching degree of asset convexity and liability convexity.

It can be seen from equation (4) that $A$, $D_{\mathrm{GAP}}=D_{A}-K D_{L}, C_{\mathrm{GAP}}=C_{A}-K C_{L}$, and $R$ are the most important factors affecting the net asset value of commercial banks; in addition, it can be learned that when the fluctuation range of interest rate is small, the influence of 
convexity on net assets can be ignored. The specific conclusions are shown in Table 1.

When the interest rate changes greatly, the influence of convexity on net assets will be highlighted; the specific conclusions are shown in Table 2.

\subsection{The Influence of Embedded Option on Duration-Convexity} Gap Model. Net assets of commercial banks are equal to assets minus liabilities; assuming that the initial net assets of commercial banks are greater than 0 , the duration and convexity of assets and liabilities are matched. The impact of the existence of embedded options on the net assets of commercial banks can be illustrated by the curve of relationship between market value of assets (liabilities) and interest rate as shown in Figure 3.

At the beginning, when banks manage interest rate risk according to the duration-convexity gap model, the asset liability structure is matched; when the interest rate changes between $R^{*}$ and $R^{* *}$, the embedded option is not executed, the bank's net assets are immune to interest rate changes, and the net assets of the bank remain unchanged at $E^{*}$. When interest rates fall below $R^{* *}$, the curve of relationship between market value of liabilities and interest rate does not change; however, the duration of bank assets decreases due to the borrower's prepayment, and the absolute value of the slope of the curve becomes smaller, that is, the convexity of assets becomes negative, which makes the rise of asset value produce bottleneck when the interest rate drops, while the convexity of liabilities will not be affected; therefore, the net asset decreases from $E^{*}$ to $E_{1}$, resulting in interest rate risk exposure.

When the interest rate rises higher than $R^{*}$, the curve of relationship between market value of assets and interest rate remains unchanged; when the interest rate rises, the depositor withdraws the deposit in advance, which leads to the decrease of the absolute value of duration and convexity of the liability, and the curve becomes gentle. The decrease speed of asset value is faster than that of liability value, which leads to the decrease of net asset value from $E^{*}$ to $E_{2}$, thus resulting in interest rate risk exposure.

Combining Figure 3 with equation (4), when the interest rate drops below $R^{* *}$, the embedded option is executed, and the duration gap $D_{\mathrm{GAP}}=D_{A}-K D_{L}$ becomes negative, which means that the bank's net asset value decreases when the interest rate drops; in addition, when the embedded option is executed, the convexity gap $C_{\mathrm{GAP}}=C_{A}-K C_{L}$ becomes negative, and the net asset value of the bank decreases when the interest rate drops.

When the interest rate is higher than $R^{*}$, the embedded option is executed, and the duration gap $D_{\mathrm{GAP}}=D_{A}-K D_{L}$ becomes positive, and the bank's net asset value decreases when the interest rate rises; meanwhile, the convexity gap $C_{\mathrm{GAP}}=C_{A}-K C_{L}$ also becomes positive, and the bank's net asset value decreases when the interest rate rises.

From the above analysis, we can see that whether the market interest rate rises or falls, the existence of embedded options will lead to the decrease of net asset value of commercial banks, and such embedded options are valuable to customers. Commercial banks often ignore the existence of embedded options and give them to customers free of charge, thus reducing their own profits. In addition, embedded options will also cause duration mismatch and convexity mismatch between assets and liabilities, and the traditional duration and traditional convexity are not accurate in measuring interest rate risk, so we need to introduce more effective measurement tools, namely, effective duration and effective convexity.

\subsection{Calculation of Effective Duration and Effective Convexity} Based on Embedded Options. When assets and liabilities contain embedded options, the traditional duration and traditional convexity will lose accuracy in measuring interest rate risk; it needs to be replaced by effective duration $\left(D_{\text {eff }}\right)$ and effective convexity $\left(C_{\text {eff }}\right)$, and their expressions are as follows:

$$
\begin{aligned}
D_{\text {eff }} & =\frac{P_{+}-P_{-}}{2 \Delta r P_{0}}, \\
C_{\text {eff }} & =\frac{P_{+}-2 P_{0}+P_{-}}{\Delta r^{2} P_{0}},
\end{aligned}
$$

where $\Delta r$ is the interest rate spread expressed by base point; $P_{0}$ is the initial bond value; and $P_{-}$and $P_{+}$are the bond prices when the interest rate moves downward and upward by a certain basis point, respectively.

$$
\begin{aligned}
& P_{-}=\frac{1}{m} \sum_{j=1}^{m} \sum_{t=1}^{n} \frac{\mathrm{CF}_{t}^{j}}{\prod_{i=1}^{t}\left(1+r_{i}^{j}-\Delta r+\mathrm{OAS}\right)}, \\
& P_{+}=\frac{1}{m} \sum_{j=1}^{m} \sum_{t=1}^{n} \frac{\mathrm{CF}_{t}^{j}}{\prod_{i=1}^{t}\left(1+r_{i}^{j}+\Delta r+\mathrm{OAS}\right)},
\end{aligned}
$$

where $m$ is the total number of interest rate change paths; $t$ is the time when the cash flow is generated; $j$ is the $j$-th path of interest rate change; $n$ is the total contract term; $\mathrm{CF}_{t}^{j}$ is the $t$-th cash flow under the $j$-th interest rate path; $r_{i}^{j}$ is the $i$-th market interest rate under the $j$-th interest rate path; and OAS is the option-adjustment spread [9], which is the basis for the calculation of effective duration and effective convexity. Specifically, OAS is the bond risk compensation when the bond market value is equal to the theoretical value, which mainly refers to the credit risk, liquidity risk, and other risk compensation after excluding the embedded option risk; it can be calculated by the following equation:

$$
P=\frac{1}{m} \sum_{j=1}^{m} \sum_{t=1}^{n} \frac{\mathrm{CF}_{t}^{j}}{\prod_{i=1}^{t}\left(1+r_{i}^{j}+\mathrm{OAS}\right)},
$$

where $P$ represents the bond market price; $1 / m$ is the mean value under the risk neutral probability measure; and $\mathrm{CF}_{t}^{j}$ and $r_{i}^{j}$ have the same meanings as above. 


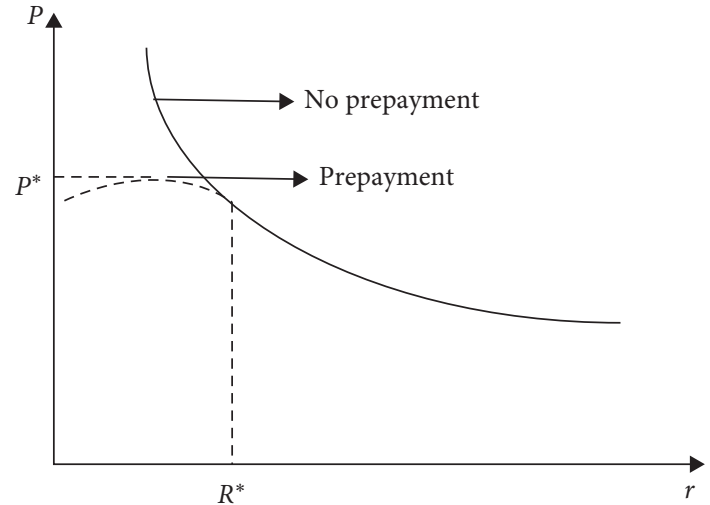

Figure 1: The curve of relationship between market value of mortgage and interest rate.

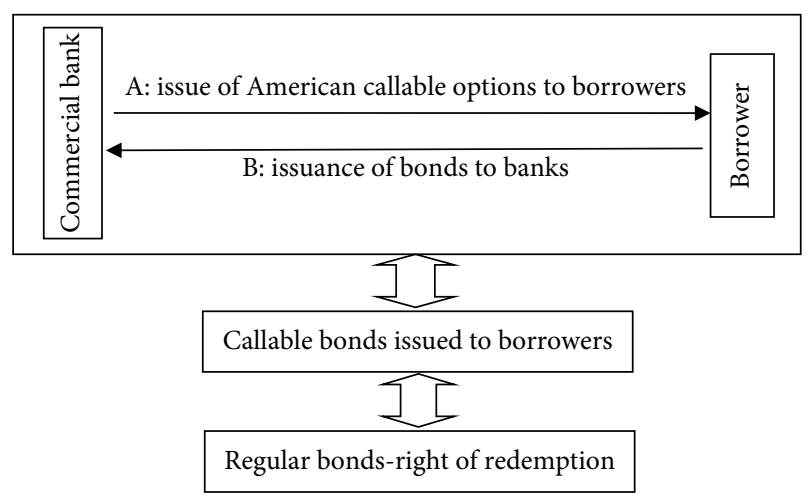

Figure 2: Decomposition of housing mortgage business.

The calculation flow of OAS in equation (9) is shown in Figure 4.

The calculation of OAS depends on the simulation of interest rate path [10]; when simulating the interest rate path, the selected interest rate model should not only meet the initial interest rate term structure but also conform to the assumed stochastic process [11]. Based on the calculated cash flow and discount factor, $P_{-}$and $P_{+}$are obtained, and then the effective duration and effective convexity are calculated.

3.4. Selection of HPL-MC in the Calculation of Effective Duration and Effective Convexity. There are many different methods to select and simulate the sample interest rate path mentioned above, such as the trigeminal tree method, excel table method, and Monte Carlo simulation method. In this paper, the Monte Carlo simulation method is used to simulate the sample interest rate path and calculate the value of OAS.

Using MC to calculate the price, effective duration, and effective convexity of securities with embedded option is actually to calculate the multidimensional numerical integration on the path space of a sample interest rate. The random number sequence generated by traditional $\mathrm{MC}$ is unevenly distributed in the simulation space, which leads to the clustering effect of random numbers, wastes a large number of observations, and reduces the computational efficiency; therefore, some scholars have proposed the quasiMC (QMC) method, which uses the predetermined deterministic method to generate some low deviation points in space to replace the independent random points in Monte Carlo simulation. Due to the uniform distribution of these simulation points in space, it can produce better convergence effect with less simulation times. The research shows that QMC simulation can produce obvious improvement effect only when the maintenance simulation is low, and sometimes the simulation effect is not as good as MC simulation when the simulation dimension is high [12]; therefore, a hybrid method for generating interest rate path of QMC and MC, HPL-MC, is proposed.

The method is based on the principal component method. It is assumed that the simulation interval $[0, T]$ is divided into dimension $d$, i.e., $0=t_{0}<t_{1}<\cdots<t_{d}=T$. The simulated interest rate path is a Wiener vector $W^{t}=\left(w_{1}^{t}, w_{2}^{t}, \ldots, w_{d}^{t}\right)^{T}$, where $A$ is the transformation matrix, and $Z=\left(z_{1}, z_{2}, \ldots, z_{d}\right)^{T}$. Suppose that the covariance matrix of the standard normal vector $Z_{i}$ is $\Sigma$; then, $\Sigma=A A^{T}$. Principal component analysis is used to construct a matrix $B$ so that $B B^{T}=A A^{T}=\Sigma$, and each standard normal variable produced by $w_{t}=B Z$ can reveal the information contained in all the original $d$ standard normal variables to the maximum extent. According to the idea of principal component analysis, matrix $B$ should be in the following form: $B=V \Lambda$; among them, the matrix $\Lambda$ is a diagonal matrix composed of the square roots of all eigenvalues of $\Sigma$, the order of the square roots of eigenvalues is from large to small along the diagonal, all column vectors of matrix $\Lambda$ are the unionized eigenvectors of matrix $\Sigma$, and the $i$-th column vector corresponds to the $i$-th eigenvalue on the diagonal of matrix $V$.

After getting the matrix, HPL-MC generates the first $k$ term quasirandom numbers $z_{i}^{*}(i=1,2, \ldots, k)$ with QMC and then generates the remaining $d-k$ dimensional pseudorandom numbers $z_{i}(i=k+1, k+2, \ldots, d)$ by MC simulation. In this way, the resulting hybrid analog sequence is

$$
W_{i}=\sum_{i=1}^{k} b_{i} z_{i}^{*}+\sum_{i=k+1}^{d} b_{i} z_{i}
$$

where $b_{i}$ is the column vector of matrix $B$.

The hybrid sequence not only ensures that the principal component terms which play a leading role in the fluctuation properties of the sequence can be evenly distributed in space but also avoids the disadvantage that QMC has no obvious effect in simulating high-dimensional sequences so as to improve the simulation accuracy and speed up the convergence speed.

\section{An Empirical Analysis of Interest Rate Risk Measurement of Financial Instruments with Embedded Option}

This part takes the financial instruments with embedded option in American capital market as an example, which is 
TABLE 1: Interest rate risk faced by duration gap.

\begin{tabular}{|c|c|c|}
\hline Duration gap & The direction of interest rate change & Changes in net assets \\
\hline Positive number & $\begin{array}{c}\text { Rise } \\
\text { Decline }\end{array}$ & $\begin{array}{c}\text { Decline } \\
\text { Rise }\end{array}$ \\
\hline Negative & $\begin{array}{l}\text { Rise } \\
\text { Decline }\end{array}$ & $\begin{array}{l}\text { Decline } \\
\text { Rise }\end{array}$ \\
\hline
\end{tabular}

TABLE 2: Interest rate risk faced by convexity gap.

\begin{tabular}{|c|c|c|}
\hline Convexity gap & The direction of interest rate change & Changes in net assets \\
\hline \multirow{2}{*}{ Positive number } & Rise & Rise \\
\hline & Decline & Rise \\
\hline \multirow{2}{*}{ Negative } & Rise & Decline \\
\hline & Decline & Decline \\
\hline
\end{tabular}

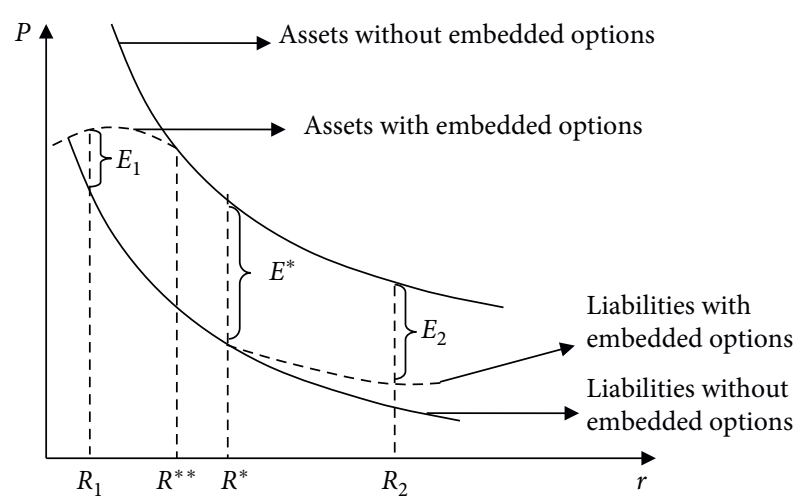

FIgURE 3: The curve of relationship between market value of assets (liabilities) and interest rate.

mortgage-backed security (MBS). MBS is a kind of fixed income securities, which has obvious option characteristics; its future cash flow is affected by many factors such as market interest rate, loan type, macroeconomic situation, and season, which will bring interest rate risk of embedded option to commercial banks and other financial institutions. Before the empirical analysis of MBS, we need to determine prepayment model of MBS, cash flow model of MBS, and term structure models of interest rates.

4.1. The Prepayment Model of MBS. OTS's prepayment model of MBS [13], Richard and Roll's prepayment model, and improved Goldman Sachs model are used for reference, and it is concluded that the prepayment rate is related to four main factors, namely, refinancing incentives, seasoning or age of the mortgage factor, seasonality or the month factor, and burnout factor. If CPR (conditional annual prepayment rate) is used to represent the annual mortgage prepayment rate, then CPR is the product of the above four factors; the expression is as follows:

$\mathrm{CPR}=$ (refinancing incentives) $*$ (seasoning factor)

* (seasonality factor) * (burnout factor).
The expression of each factor (equation (11)) is as follows.

4.1.1. Refinancing Incentives. It is measured by dividing the annual weighted average coupon rate of mortgage-backed by the refinancing rate.

$$
\begin{aligned}
\mathrm{RI}(t)= & 0.31234-0.2025 \\
& \times \arctan \left[8.157 \times\left(-\frac{\mathrm{WAC}+\mathrm{SE}}{P(t)+\mathrm{F}}+1.20761\right)\right],
\end{aligned}
$$

where WAC represents the average coupon rate of MBS; $t$ represents the number of months; and SE represents the service fee rate provided by the service organization; usually a fixed ratio is drawn based on the balance of the loan pool; this ratio is generally $50-100$ basis points; here 50 basis points are taken. Let $\operatorname{Prin}(t)$ represent the book balance of the outstanding principal of the mortgage-backed bond loan agreement at the beginning of month $t$ and $S(t)$ represent the service fee paid in month $t$; then,

$$
S(t)=0.005 \times \operatorname{Prin}(t) \times \frac{1}{12}
$$

$P(t)$ represents the refinancing rate, in which the refinancing rate is represented by the ten-year zero coupon rate:

$$
P(t)=-\frac{\ln (p(t / 12, t t / 12+10))}{10} .
$$

$P(t, T)$ represents the bond price with the maturity date $T$ at time $t$; then,

$$
\begin{gathered}
p(t, T)=A(t, T) e^{-B(t, T)^{r}}, \\
B(t, T)=\frac{1-e^{-a(T-t)}}{a},
\end{gathered}
$$

$$
\begin{aligned}
\ln A(t, T)= & \ln \frac{p(0, T)}{p(0, t)}-B(t, T) \frac{\partial \ln p(0, t)}{\partial t}-\frac{1}{4 a^{3}} \sigma^{2} \\
& \cdot\left(e^{-a T}-e^{-a t}\right)^{2}\left(e^{2 a t}-1\right) .
\end{aligned}
$$




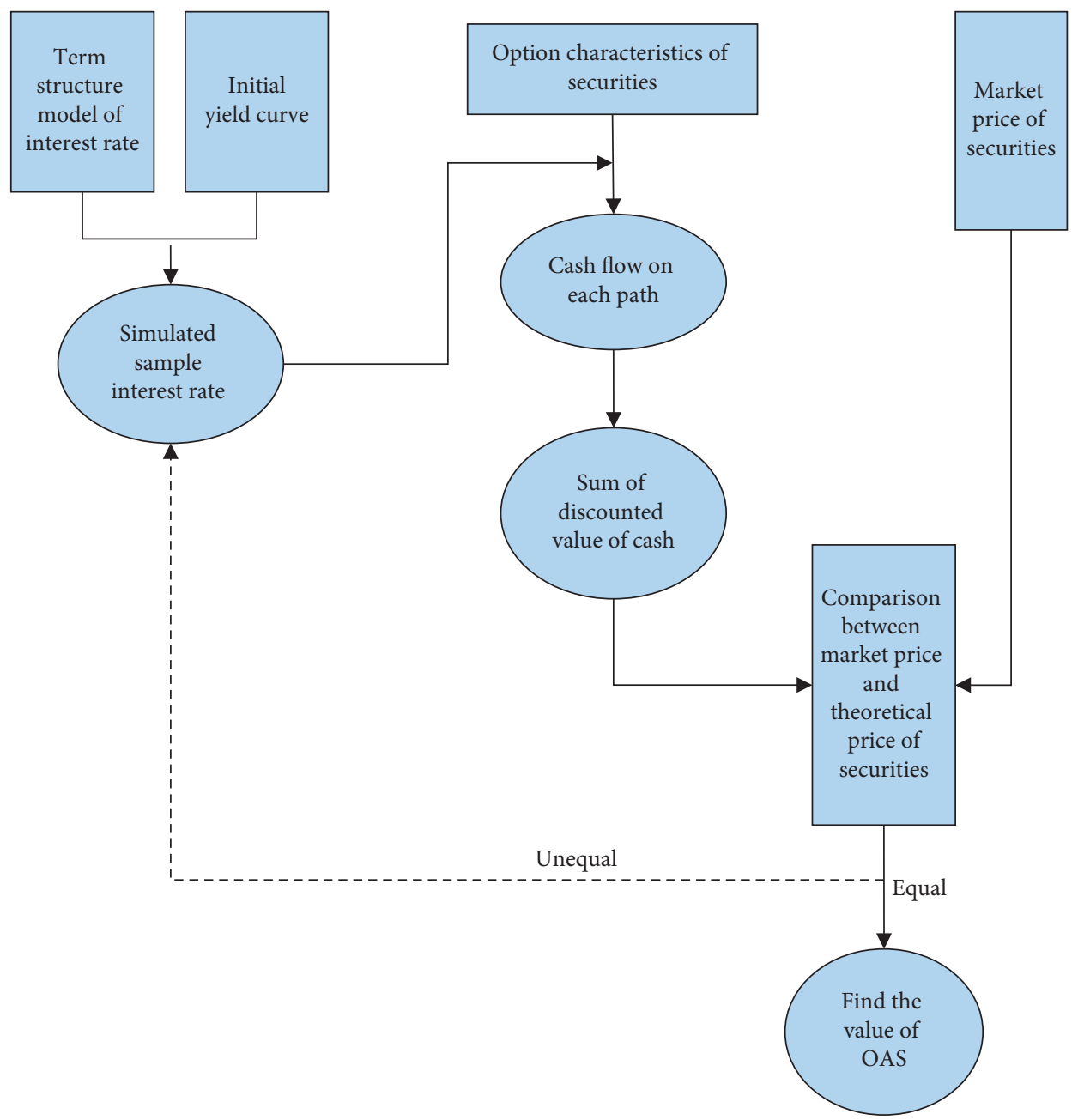

Figure 4: Calculation flow chart of option-adjusted spread.

In equation (12), $F$ represents the refinancing expenses related to refinancing mortgage loans.

4.1.2. Seasoning or Age of the Mortgage Factor. The definition of this factor by the Office of Thrift Supervision (OTS) is as follows:

$$
\operatorname{seasoning}(t)=\min (t \times 0.0333,1) \text {. }
$$

4.1.3. Seasonality Factor. The definition of this factor by the Office of Thrift Supervision (OTS) is as follows:

$$
\text { seasonality }=1+0.2 \times \sin \left\{1.571 \times\left(\frac{\text { month }+t-3}{3}\right)-1\right\} \text {, }
$$

where month is the number of months (from 1 to 12 ).

4.1.4. Burnout Factor. At present, the functional expression of this factor is not uniform, and even some prepayment models do not involve this factor. Here, the burnout factor is expressed as follows:

$$
\operatorname{burnout}(t)=e^{-0.115(\mathrm{WAC} / P(t))} \text {. }
$$

The meaning of each parameter in equation (20) is the same as before, and this factor is only calculated when the loan age factor reaches 1 ; then, the monthly conditional prepayment rate (MCPR) is expressed as follows:

$$
\operatorname{MCPR}(t)=1-(1-\operatorname{CPR}(t))^{1 / 12} .
$$

4.2. Cash Flow Model of MBS. According to the OTS model, the sum of the discounted value of the cash flow during the validity period of MBS is calculated as follows [14]:

$$
\mathrm{PV}=\sum_{i=1}^{\mathrm{WAM}} \operatorname{dis}(t) \cdot(\operatorname{TPP}(t)+\operatorname{IP}(t)+S(t))
$$

WAM in equation (22) means weighted average maturity. 
dis $(t)$ represents the discount factor of MBS in month $t$, and its expression is as follows:

$$
\operatorname{dis}(t)=\frac{1}{\prod_{i=1}^{t}(1+r(i))^{1 / 12}} .
$$

IP $(t)$ in equation (22) represents the interest paid of MBS in month $t$ :

$$
\mathrm{IP}(t)=\operatorname{Prin}(t) \cdot \frac{(\mathrm{WAC}-\mathrm{SE})}{12} .
$$

In equation (24), SE is the service rate, which is $50 \mathrm{bps}$.

In equation (22), $\operatorname{TPP}(t)$ represents the total principal paid of MBS in month $t$ :

$$
\operatorname{TPP}(t)=\operatorname{SPP}(t)+\operatorname{PA}(t)
$$

In equation (25), $\operatorname{SPP}(t)$ represents the scheduled principal paid of MBS in month $t$ :

$$
\operatorname{SPP}(t)=\operatorname{Pmt}(t)-I P(t)-S(t) .
$$

In equation (26), $\operatorname{Pmt}(t)$ represents the monthly payment of MBS in month $t$ when prepayment is considered:

$$
\operatorname{Pmt}(t)=\operatorname{Prin}(t) \cdot \frac{\mathrm{WAC} / 12}{1-\left(1 /(1+\mathrm{WAC} / 12)^{\mathrm{WAM}-t+1}\right)}
$$

When prepayment is not considered, the following equation is used:

$$
\operatorname{Pmt}(t)=\operatorname{Prin}(t) \cdot \frac{\mathrm{WAC} / 12}{1-\left(1 /(1+\mathrm{WAC} / 12)^{\mathrm{WAM}}\right)} .
$$

In equation (25), $\mathrm{PA}(T)$ represents the prepayment amount of MBS in the month $t$ :

$$
\operatorname{PA}(t)=\operatorname{MCPR}(t) \cdot \operatorname{Prin}(t)-\operatorname{SPP}(t) .
$$

In equation (29), $\operatorname{MCPR}(t)$ and $\operatorname{Prin}(t)$ have the same meanings as the variables in equations (21) and (13). In addition, the book balance of the outstanding loan principal of MBS at the beginning of month $t+1$ is

$$
\operatorname{Prin}(t+1)=\operatorname{Prin}(t)-\operatorname{SPP}(t) .
$$

In equation (30), $\operatorname{SPP}(t)$ has the same meaning as in equation (25).

\subsection{Selection of Interest Rate Term Structure}

4.3.1. Introduction of Fuzzy Stochastic Process. It should be noted that many scholars use stochastic models to describe the uncertainty of financial markets, and modern methods to deal with these stochastic models mainly include the probability theory method (mainly considering from random process) and fuzzy set method. In this paper, we combine randomness and fuzziness and consider that interest rate and volatility are fuzzy random numbers of $n$-th parabola distribution. Next, the theory of the coexistence of random and fuzzy, namely, the mixed process theory, is proposed here [15-17].

Definition 1. $\left(\Theta, P, C_{r}\right)$ is credibility space, $\left(\Omega, A, P_{r}\right)$ is probability space, and opportunity space is defined as $\left(\Theta, P, C_{r}\right) \times\left(\Omega, A, P_{r}\right)$. Then, the mixed variable is a measurable function from the chance space $\left(\Theta, P, C_{r}\right) \times\left(\Omega, A, P_{r}\right)$ to the set of real numbers. If $T$ is an index set, then a measurable function from $T \times\left(\Theta, P, C_{r}\right) \times$ $\left(\Omega, A, P_{r}\right)$ to the set of real numbers is called a mixed process.

Definition 2. If the mixing process $X_{t}$ has independent increments, if for any time $t_{0}<t_{1}<\cdots<t_{k}, X_{t_{1}}-X_{t_{0}}, X_{t_{2}}-$ $X_{t_{1}}, \ldots, X_{t_{k}}-X_{t_{k-1}}$ are independent mixed variables. If the fuzzy process $X_{t}$ has a stable increment, if $t>0$ at any time, and for any $s>0, X_{s+t}-X_{s}$ is a mixed variable with the same distribution.

Definition 3. $W_{t}$ is a Wiener process, $C_{t}$ is a Liu process (it was put forward by Liu Baoding) $[18,19]$, and $D_{t}=\left(W_{t} ; C_{t}\right)$ is called a $D$ process. When $W_{t}$ and $C_{t}$ are both standard processes, the mixing process $X_{t}=e t+\beta W_{t}+\beta^{*} C_{t}$ is a standard $D$ process, where $e, W_{t}$, and $C_{t}$ are independent of each other. The parameter $e$ is called the drift coefficient, $\beta$ is called the random diffusion coefficient, and $\beta^{*}$ is called the fuzzy diffusion coefficient.

4.3.2. The Choice of Interest Rate Model. In choosing the interest rate model, we compare and analyze the advantages of the Hull-White model (generalized Vasicek model) and Hull-White extended CIR model and finally choose Hull-White extended CIR model; the next part is the specific implementation process.

Considering that the general initial income curve is slightly upward sloping curve, the initial term structure selected in the simulation is the most typical initial term structure:

$$
f(t)=0.06+0.5 \times \frac{\ln (t)}{100}
$$

In equation (31), $f(t)$ represents the initial term structure function.

Many mathematicians have chosen the Hull-White model (generalized Vasicek model) as the term structure model of interest rate; its expression is as follows:

$$
\mathrm{d} r(t)=[\theta(t)-a r(t)] \mathrm{d} t+\sigma \mathrm{d} W_{t} .
$$

In equation (32), $a$ is a constant, which represents the mean regression rate of interest rate or the expected value of drift rate of interest rate; $\sigma$ is also a constant, representing the standard deviation of interest rate; and $W_{t}$ is a Brownian motion, which follows the Markov process; the variation of $W_{t}$ on a small time interval $\Delta t$ is represented by $\Delta W_{t}$; then, $\Delta W_{t}$ and $\Delta t$ satisfy the following relationship:

$$
\Delta W_{t}=\varepsilon \sqrt{\Delta t} .
$$


In equation (33), $\varepsilon$ is a random value taken from the standard normal distribution. For any two different time intervals of $\Delta t$, the values of $\Delta W_{t}$ are independent of each other.

In equation (32), $\theta(t)$ is the time function to ensure that the model conforms to the initial term structure; its expression is as follows:

$$
\theta(t)=\frac{\mathrm{d} f(t)}{\mathrm{d} t}+a f(t)+\frac{\sigma^{2}}{2 a}\left(1-e^{-2 a t}\right) .
$$

The Hull-White model (generalized Vasicek model) has a significant drawback, that is, the interest rate simulated by the model may be negative. Therefore, in order to make up for the defect that the interest rate may be negative and make the model conform to the initial yield curve accurately, the Hull-White extended CIR model is selected as follows:

$$
\mathrm{d} r(t)=[\theta(t)-a f(t)] \mathrm{d}(t)+\sigma \sqrt{r(t)} \mathrm{d} W_{t} .
$$

In equation (35), $\theta(t)$ is the time function to ensure that the model conforms to the initial term structure; the interest rate volatility in this model is different from that in the previous model; therefore, the following expression is obtained:

$$
\mathrm{d} r(t)=\frac{\mathrm{d} f(t)}{\mathrm{d} t}+a f(t)+\frac{\sigma^{2} r(t)}{2 a}\left(1-e^{-2 a t}\right) .
$$

$\sigma \sqrt{r(t)}$ in equation (35) represents the volatility of interest rates, that is, the standard deviation of interest rates [20-22].

Although the Hull-White extended CIR model is more complicated than the Hull-White model (generalized Vasicek model), the Hull-White extended CIR model can solve the problem of negative $r$.

In order to more clearly illustrate the advanced nature of the Hull-White extended CIR model, we compare the simulation results shown in Figure 5, where the asterisk line is the interest rate value simulated under the generalized Vasicek model and the grid line is the interest rate value simulated under the Hull-White extended CIR model.

It can be clearly seen from Figure 5 that when the Hull-White extended CIR model is adopted, the possible negative interest rate can be effectively avoided.

When simulating the path of interest rate $r$, equation (33) needs to be discretized as follows:

$$
r(t+1)-r(t)=[\theta(t)-\operatorname{ar}(t)]+\sigma \sqrt{r(t)} \Delta W_{t} .
$$

The selected initial term structure is brought into equation (34) to get the following equation:

$$
\theta(t)=\frac{1}{2 t}+a\left(0.06+0.5 \times \frac{\ln (t)}{100}\right)+\frac{\sigma^{2} r(t)}{2 a}\left(1-e^{-2 a t}\right) .
$$

Incorporating equation (38) into equation (37) gives the following equation:

$$
\begin{aligned}
r(t+1)= & r(t)+\left[\frac{1}{2 t}+a\left(0.06+0.5 \times \frac{\ln (t)}{100}\right)\right. \\
& \left.+\frac{\sigma^{2} r(t)}{2 a}-\operatorname{ar}(t)\right] \Delta t+\sigma \sqrt{r(t)} \varepsilon \sqrt{\Delta t} .
\end{aligned}
$$

Among them, $\Delta t_{i}=t_{i+1}-t_{i}$ is fuzzy random variable, which can be realized by the value of fuzzy random number function.

Let us estimate the value of $\sigma$ and write $\sigma r^{1 / 2}$ in the model as follows:

$$
\sigma_{r}=\sigma r^{1 / 2} .
$$

According to historical data, the average volatility $\sigma_{r}$ of interest rates in the US market is 0.01 , and the average yield of short-term Treasury bills is 0.06 , so the value of $\sigma$ in equation (39) can be determined based on historical data.

Transform equation (40) as follows:

$$
\ln \left(\sigma_{r}\right)=\ln \sigma+1 / 2 \ln r .
$$

It can be seen that there is a linear relationship between $\ln \sigma_{r}$ and $\ln \sigma$, and the estimated value of $\sigma$ can be determined by the method of linear regression; through the calculation of historical data, the estimated value of $\sigma$ is 0.041 .

In this way, by combining the prepayment model and cash flow model mentioned above, effective duration and effective convexity can be calculated through simulation.

4.4. Empirical Simulation and Result Analysis. This article takes mortgage-backed bonds in the U.S. securities market as an example, which is issued on the basis of a loan pool called FNCL702342, the weighted average coupon rate of this loan pool is 0.05888 , the weighted average maturity is 360 months, and the face price is $\$ 100$.

4.4.1. Graphic Analysis of Simulation Results. Through the simulation calculation of FNCL702342 and the data obtained by MATLAB, the final results are as follows.

When prepayment is not considered, the cash flow chart of MBS is shown in Figure 6.

It can be seen that when the prepayment rate is 0 , that is, there is no embedded option (as shown in Figure 6), the monthly repayment of principal and interest is a constant, and the monthly interest repayment amount and the monthly service fee payable decrease month by month; therefore, the monthly principal repayment amount increases month by month.

When the prepayment factor is considered, the cash flow chart of MBS is shown in Figure 7.

Due to the existence of prepayment of principal, the monthly cash flow will change. In this case, the monthly planned repayment of principal and interest is no longer a constant, but slowly decreases month by month, and the amount of prepayment of principal also decreases. Due to the existence of prepayment of principal, the total monthly principal repayment has increased. 


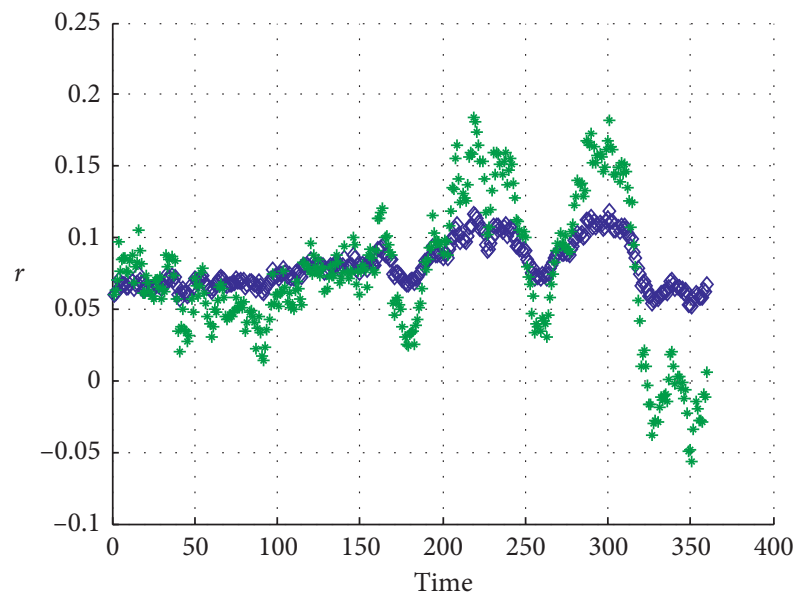

FIGURE 5: Comparison of interest rates simulated by generalized Vasicek model and extended CIR model.

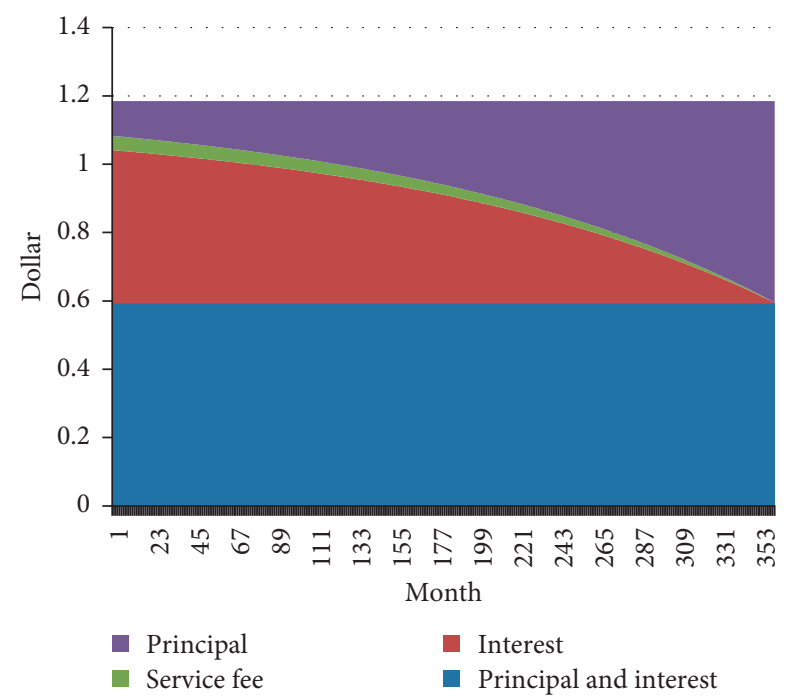

FIGURE 6: Cash flow chart without prepayment.

4.4.2. Calculation of OAS, Effective Duration, and Effective Convexity of MBS Based on HPL-MC. In the actual simulation, QMC is used to simulate the random terms corresponding to the eigenvalues of the first $k$ terms $(k=8,12)$, and $\mathrm{MC}$ is used to simulate the remaining random terms. In the empirical simulation of FNCL702342, we take the theoretical price obtained by MC simulation for 40000 times as the real value of the security price to observe the simulation convergence; taking $k=8$ and $k=12$, we use HPL-MC to simulate the interest rate path, and the results are shown in Table 3.

It can be found from Table 3 that no matter what the value of $k$ is, the results of HPL-MC simulation are better than those of MC simulation, and the effect of MC simulation for 5000 times is only equivalent to that of HPL-MC simulation of 1000 times. In addition, the higher the value of $k$, the better the simulation effect and the faster the

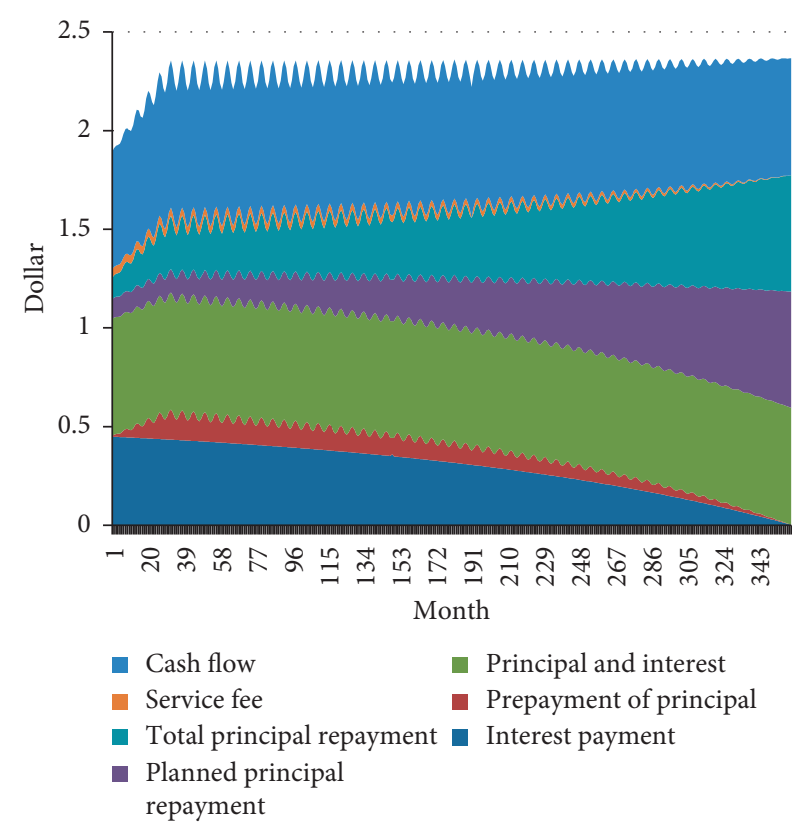

FIgURE 7: Cash flow chart with prepayment.

convergence speed. When $k=12$, the OAS of MBS is 0.0264 , that is, 264 basis points. After adding and subtracting 5 basis points to the adjusted discount rate of options, the corresponding securities prices are calculated to be 85.7796 and 86.3163 , respectively, and the effective duration is 6.3148 and the effective convexity is -717.6643 . Without considering the prepayment factor, the traditional Macaulay duration of MBS is 9.6022; it can be found that the effective duration of MBS with embedded option is much smaller than the traditional duration, that is, the value of securities is more sensitive to the change of interest rate.

Because of this difference, when there are implicit options in the assets or liabilities of a bank, if the traditional Macaulay duration is still used to measure and manage the interest rate risk and the duration gap is zero, on the surface, it seems that the bank has realized the risk immunity, but in fact, the real duration gap is not zero, and the interest rate risk is not really eliminated.

4.5. Asset Liability Management Cases of Commercial Banks with Embedded Options. The empirical study here is based on the MBS with embedded option characteristics; however, there are also embedded options in the assets and liabilities of commercial banks, such as time deposits that can be drawn in advance and loans that can be repaid in advance. At this time, if commercial banks use the traditional duration gap method to manage interest rate risk, the apparent duration gap is zero, the actual duration gap is not zero, and there is still interest rate risk exposure. In other words, if there are embedded options in the balance sheet of commercial banks, the traditional Macaulay duration will lose its effectiveness in gap management. Here we will choose a case to demonstrate the effectiveness of effective duration in managing interest rate risk when there are embedded options. 
TABLe 3: Simulation results of MC and HPC.

\begin{tabular}{|c|c|c|c|c|c|c|c|c|}
\hline \multirow{2}{*}{\multicolumn{3}{|c|}{$\begin{array}{c}\text { Simulation parameters } \\
\text { Simulation times }\end{array}$}} & \multicolumn{6}{|c|}{$f(t)=0.05888, a=0.3$, and $\sigma=0.041$} \\
\hline & & & \multirow{2}{*}{$\frac{100}{86.8452}$} & \multirow{2}{*}{$\frac{500}{86.8546}$} & \multirow{2}{*}{$\frac{1000}{86.5955}$} & \multirow{2}{*}{$\begin{array}{c}5000 \\
86.3424\end{array}$} & \multirow{2}{*}{$\begin{array}{c}10000 \\
86.1682\end{array}$} & \multirow{2}{*}{$\frac{40000}{86.0492}$} \\
\hline \multirow{3}{*}{ Simulation method } & \multicolumn{2}{|c|}{$\mathrm{MC}$} & & & & & & \\
\hline & \multirow{2}{*}{ HPL-MC } & $K=8$ & 86.2644 & 86.2614 & 86.1546 & 86.0982 & 86.0479 & \\
\hline & & $K=12$ & 86.2346 & 86.2245 & 86.1525 & 86.0979 & 86.0487 & \\
\hline
\end{tabular}

TABLE 4: Balance sheet of a commercial bank.

\begin{tabular}{lccccccc}
\hline Assets & $\begin{array}{c}\text { Market } \\
\text { value }\end{array}$ & $\begin{array}{c}\text { Interest } \\
\text { rate }\end{array}$ & $\begin{array}{c}\text { Macaulay } \\
\text { duration }\end{array}$ & $\begin{array}{c}\text { Liabilities and shareholders' } \\
\text { equity }\end{array}$ & $\begin{array}{c}\text { Market } \\
\text { value }\end{array}$ & $\begin{array}{c}\text { Interest } \\
\text { rate }\end{array}$ & $\begin{array}{c}\text { Macaulay } \\
\text { duration }\end{array}$ \\
\hline $\begin{array}{l}\text { Cash } \\
\text { 30-year }\end{array}$ & 200 & 0 & 0 & 10 -year deposit & 200 & 0.06 & 7.8016 \\
FNMA & 300 & 0.05888 & 9.6022 & 3-year deposit & 1000 & 0.05 & 8.1077 \\
10-year loan & 1000 & 0.1 & 6.7588 & Total liabilities & 1200 & 8.0566 \\
Total & 1500 & & 6.4264 & $\begin{array}{c}\text { Shareholders' equity } \\
\text { Total }\end{array}$ & 300 & 1500 \\
\end{tabular}

TABLE 5: Adjusted balance sheet of a commercial bank.

\begin{tabular}{|c|c|c|c|c|c|c|c|}
\hline Assets & $\begin{array}{l}\text { Market } \\
\text { value }\end{array}$ & $\begin{array}{l}\text { Interest } \\
\text { rate }\end{array}$ & $\begin{array}{c}\text { Macaulay } \\
\text { duration }\end{array}$ & $\begin{array}{l}\text { Liabilities and shareholders' } \\
\text { equity }\end{array}$ & $\begin{array}{c}\text { Market } \\
\text { value }\end{array}$ & $\begin{array}{l}\text { Interest } \\
\text { rate }\end{array}$ & $\begin{array}{l}\text { Macaulay } \\
\text { duration }\end{array}$ \\
\hline Cash & 200 & 0 & 0 & 10-year deposit & 293 & 0.06 & 7.8016 \\
\hline $\begin{array}{l}\text { 30-year } \\
\text { FNMA }\end{array}$ & 300 & 0.05888 & 9.6022 & 3-year deposit & 907 & 0.05 & 8.1077 \\
\hline 10-year loan & 1000 & 0.1 & 6.7588 & Total liabilities & 1200 & & 8.0332 \\
\hline Total & 1500 & & 6.4264 & $\begin{array}{c}\text { Shareholders' equity } \\
\text { Total }\end{array}$ & $\begin{array}{c}300 \\
1500\end{array}$ & & \\
\hline
\end{tabular}

TABLE 6: Balance sheet and effective duration of a commercial bank.

\begin{tabular}{lccccccc}
\hline Assets & $\begin{array}{c}\text { Market } \\
\text { value }\end{array}$ & $\begin{array}{c}\text { Interest } \\
\text { rate }\end{array}$ & $\begin{array}{c}\text { Macaulay } \\
\text { duration }\end{array}$ & $\begin{array}{c}\text { Liabilities and shareholders' } \\
\text { equity }\end{array}$ & $\begin{array}{c}\text { Market } \\
\text { value }\end{array}$ & $\begin{array}{c}\text { Interest } \\
\text { rate }\end{array}$ & $\begin{array}{c}\text { Macaulay } \\
\text { duration }\end{array}$ \\
\hline $\begin{array}{l}\text { Cash } \\
\text { 30-year }\end{array}$ & 200 & 0 & 0 & 10 -year deposit & 293 & 0.06 & 7.8016 \\
FNMA & 300 & 0.05888 & 6.3148 & 3-year deposit & 907 & 0.05 \\
10-year loan & 1000 & 0.1 & 6.7588 & Total liabilities & 1200 & 8.1077 \\
Total & 1500 & & \multicolumn{5}{c}{$\begin{array}{c}\text { Thareholders' equity } \\
\text { Total }\end{array}$} \\
\hline
\end{tabular}

Suppose that the initial assets of commercial bank $A$ are cash, 30-year FNCL, and 10-year loan, and the liabilities are 10-year deposit and 3-year deposit. The duration value of each asset and liability is shown in Table 4. Finally, according to the calculation equation of duration gap, that is, $D_{\mathrm{GAP}}=D_{A}-K D_{L}$, the duration gap of bank $A$ is -0.01879 (the calculation process is omitted).

According to the equation $\Delta E=-\left(D_{A} \cdot P_{A}-D_{L} \cdot P_{L}\right) \cdot(\Delta R / 1+R)$, since the duration gap is less than 0 , when the interest rate moves downward, the net asset value of the bank will decrease. In order to make the net asset value of the bank unaffected by the change of interest rate, it is necessary to adjust the structure of the bank's assets or liabilities so that its duration gap is about 0 . We adopt the method of adjusting the debt structure to get the following (Table 5).

After adjustment, the 10-year deposit is 3 million yuan, and the 3 -year deposit is 9 million yuan. According to the calculation equation of duration gap, which is $D_{\mathrm{GAP}}=D_{A}-K D_{L}$, the duration gap of bank $\mathrm{A}$ is -0.00004 . Only from the perspective of traditional duration, the duration gap of bank $A$ can be approximately zero, that is, the immunity of interest rate risk has been basically realized. However, considering the prepayment nature of FNCL, the effective duration gap is used to measure the interest rate risk of FNCL under the existing asset liability structure, and Table 6 is obtained.

As the 30-year FNCL has the characteristics of prepayment, its effective duration becomes 6.3148, and the effective duration of other assets and liabilities is the same as the traditional duration. Similarly, according to the duration gap calculation equation, the duration gap of bank $A$ is -0.6582 .

It can be seen that the duration gap of bank $A$ is not zero, and the bank is still exposed to interest rate risk. As the duration gap is negative, when the interest rate drops, the net 
asset value of the bank will decrease. Therefore, once there are embedded options, the banks which are immune to interest rate risk will have risk exposure. Therefore, for commercial banks with embedded options in assets and liabilities, the effective duration is more accurate and effective in measuring and managing interest rate risk.

\section{Conclusions}

This paper takes the financial instruments with embedded options as the research object, empirically analyzes the relevant characteristics of prepayable mortgage-backed bonds under the background of frequent interest rate fluctuations, and, on this basis, demonstrates the effectiveness of effective duration in managing interest rate risk of commercial bank. The conclusions are as follows.

On the premise that the change of interest rate follows the fuzzy stochastic process, this paper selects the Hull-White extended CIR model through comparative analysis. From the result chart of empirical simulation, the Hull-White extended CIR model can effectively solve the problem that interest rate may be negative in Monte Carlo simulation, and the effect of the Hull-White extended CIR model is better.

In Monte Carlo simulation, the random number sequence generated by traditional $\mathrm{MC}$ is unevenly distributed in the simulation space, and QMC simulation can produce obvious improvement effect only in lower dimensional simulation. Therefore, the HPL-MC method, which is a hybrid of QMC and MC, is adopted. From the simulation results, no matter what the value of $k$, the results of HPL-MC simulation are better than those of MC simulation.

When the prepayment of MBS is considered, the embedded option will lead to the decrease of bond duration and the value of MBS is more sensitive to the change of interest rate.

Under the condition of continuous innovation of financial derivatives and marketization of interest rate, interest rates fluctuate more frequently and fiercely. In the process of asset and liability management, effective duration can reduce interest rate risk exposure position and complete the task of interest rate risk management.

\section{Data Availability}

No data were used to support this study.

\section{Conflicts of Interest}

The authors declare that they have no conflicts of interest.

\section{Acknowledgments}

This study was supported by the Humanities and Social Sciences Project of Anhui Education Department (SK2018A0520) and Anhui Province Scientific Office's Soft Scientific Research Project (1706a02020042).

\section{References}

[1] K. Drakos, "Assessing the success of reform in transition banking 10 years later: an interest margins analysis," Journal of Policy Modeling, vol. 25, no. 3, p. 309, 2003.

[2] A. G. Cornyn and R. A. Klein, Controlling and Managing Interest-Rate Risk, NYIF, New York, NY, USA, 1997.

[3] W. Brent and J. Richard, "Embedded options in the mortgage contract," Pennsylvania University, Philadelphia, PA, USA, Working Paper 305, 1998.

[4] R. Brooks, "Computing yields on enhanced CDs," Financial Services Review, vol. 5, no. 1, pp. 31-42, 1996.

[5] H. Ben-Ameur, M. Breton, and L. Karoui, "A dynamic programming approach for pricing options embedded in bonds," Journal of Economic Dynamics \&Control, vol. 31, no. 7, pp. 2212-2233, 2007.

[6] Z. Zheng and L. Hai, "Decomposition and pricing of embedded options in assets and liabilities of bank," Financial Research, no. 7, pp. 24-32, 2004, in Chinese.

[7] H. Xia, M. Zhou, and X. Wang, "The influence of embedded options in deposit and loan on interest rate risk of commercial banks in China," Financial Research, no. 9, pp. 138-150, 2007, in Chinese.

[8] C. Wang and W. Zhang, "Interest rate risk measurement and management of commercial banks with embedded options: convexity gap model," Journal of Management Science, vol. 10, pp. 21-29, 2001, in Chinese.

[9] Y. Fan, M. Gu, and X. Zheng, "Application of option adjusted spread model (OAS) in interest rate risk management of commercial banks," Technology and Management, no. 2, pp. 72-75, 2003, in Chinese.

[10] R. W Kopparasch, "Option-adjusted spread analysis:going down the wrong path?" Financial Analysis Journal, vol. 50, no. 3, pp. 42-47, 1994.

[11] R. Chen and X. Guo, "Research on option adjusted spread (OAS) and its application," Financial Analysis Journal, vol. 8, pp. 24-33, 1992, in Chinese.

[12] C. Wang, Financial Market Risk Management, Tianjin University Press, Tianjing, China, 2001, in Chinese.

[13] Office of Thrift Supervision, The OTS Net Portfolio Value Model, OTS, Washington, DC, USA, 1994.

[14] J. Daniel, "A fixed-rate loan prepayment model for Australian mortgages," Australian Journal of Management, vol. 35, no. 1, pp. 99-112, 2010.

[15] H. Liu, S. Li, H. Wang, and Y. Sun, "Adaptive fuzzy control for a class of unknown fractional-order neural networks subject to input nonlinearities and dead-zones," Information Sciences, vol. 454-455, pp. 30-45, 2018.

[16] H. Liu, S. Li, H. Wang, and G. Li, "Adaptive fuzzy synchronization for a class of fractional-order neural networks," Chinese Physics B, vol. 26, no. 3, Article ID 030504, 2017.

[17] B. Liu, "Fuzzy process, hybrid process and uncertain process," Journal of Uncertain Systems, vol. 2, no. 1, pp. 3-16, 2008.

[18] Z. Zmeskal, "Application of the fuzzy-stochastic methodology to appraising the firm value as a," European Journal of Operational Research, vol. 135, no. 2, pp. 303-310, 2001.

[19] Y. Yoshida, M. Yasuda, J.-i. Nakagami, and M. Kurano, "A new evaluation of mean value for fuzzy numbers and its application to American put option under uncertainty," Fuzzy Sets and Systems, vol. 157, no. 19, pp. 2614-2626, 2006.

[20] H.-C. Wu, "European option pricing under fuzzy environments," International Journal of Intelligent Systems, vol. 20, no. 1, pp. 89-102, 2005. 
[21] C. Lee, G. Tzeng, and S. Wang, "A new application of fuzzy set theory to the Black-Scholes option pricing model," Expert Systems with Applications, vol. 29, no. 2, pp. 330-342, 2005.

[22] S. Muzzioli and C. Torricelli, "A multiperiod binomial model for pricing options in a vague world," Journal of Computational and Applied Mathematics, vol. 223, no. 2, pp. 552-566, 2009. 